\title{
EL NARRADOR EN LA TRADUCCIÓN DE LA LITERATURA INFANTIL Y JUVENIL: LAS ADAPTACIONES LITERARIAS DE EL QUIJOTE AL INGLÉS
}

\author{
Beatriz M. ${ }^{a}$ Rodríguez Rodríguez \\ Universidad de Vigo
}

\begin{abstract}
RESUMEN: El análisis de traducciones y adaptaciones literarias de obras canónicas adultas dirigidas a un público infantil y juvenil revela modificaciones importantes. Estas modificaciones pueden implicar cambios en la estrategia narrativa que se deben evaluar teniendo en cuenta factores entre los que destacan el lector implícito del texto meta, una posible intención pedagógica y el género literario del texto meta. Este trabajo analiza las causas de las divergencias en cuanto a la figura del narrador identificadas en varias adaptaciones literarias al inglés de El Quijote de la Mancha (1605) para niños y jóvenes en las que la visibilidad del adaptador se refleja claramente en su estrategia narrativa, puesto en algunos casos el narrador se convierte en un personaje más del relato. Los cambios en la estrategia narrativa permiten acercar este clásico de las letras universales al receptor infantil y juvenil.

PALABRAS CLAVE: Adaptación, LIJ, narrador, Don Quijote, intención, receptor.
\end{abstract}

\section{THE NARRATOR IN THE TRANSLATION OF CHILDREN'S LITERATURE: LITERARY ADAPTATIONS OF DON QUIXOTE INTO ENGLISH}

ABSTRACT: The analysis of literary translations and adaptations of a canonical work for children or young adults shows great divergences from the source text. Narrative strategy, for example, can be modified taking into account the implicit target text reader, possible didactic purposes and the target text literary genre, among other factors. This work aims to study the reasons for adaptors to have modified the narrator in several literary adaptations of Don Quixote (1605). The adaptor's visibility is clearly shown in the role of the narrator, who even becomes a character of the tale so as to engage the implicit target reader. Narrative strategy serves as a means of introducing the children or young adults to this classic book.

KEYWORDS: Adaptation, children's literature, narrator, Don Quixote, intention, reader. 


\section{Introducción}

Las particularidades de la literatura infantil y juvenil (LIJ) permiten que el traductor realice cambios y modificaciones atendiendo a razones sociales, educativas y estéticas (0'Sullivan 2003: 198; Shavit 2006). No cabe duda de que el lector condiciona en gran medida las decisiones del traductor o del adaptador, ya que éste debe tener en cuenta la edad del receptor y sus capacidades intelectuales y cognitivas, además de la intención del traductor, el contexto histórico y otros factores que influyen en el proceso de traducción (Toledano 2001-2002: 107). Esta visibilidad del traductor (Venuti 1995) puede quedar patente, como O’Sullivan sugiere, en la presencia del narrador en la traducción de textos de LIJ (2003: 198). Este trabajo pretende analizar las modificaciones en cuanto al papel del narrador en la traducción de la LIJ con la intención de evaluarlas y determinar cómo afectan al texto meta. Para ello se ha tenido en cuenta el modelo de comunicación narrativa propuesto por 0'Sullivan (2003) basado en el modelo de Chatman (1978). Según este modelo el autor implícito adulto crea un lector implícito basado en sus presuposiciones y las capacidades e intereses del lector. El traductor crea un texto meta que los lectores meta puedan comprender y que siga las convenciones lingüísticas y culturales. El traductor interpreta el texto y adopta métodos y estrategias de trasvase concretos que se ajustan al lector implícito de la traducción. Este lector implícito de la traducción se asemeja al lector implícito del texto fuente, aunque también ser diferente, como suele suceder en los relatos de ficción. En el caso concreto de los textos de LIJ se debe tener en cuenta qué quieren leer los niños, cuáles son las capacidades lingüísticas y cognitivas y qué es apropiado para ellos. El traductor es el que relaciona el lector del texto meta con el autor del texto fuente y el que crea el narrador y la persona a la que se dirige el texto, el lector implícito del texto meta, que puede ser paralelo al texto fuente o diferente. La identificación de estas divergencias y su análisis permiten entender la estrategia narrativa y valorarla (0’Sullivan 2003: 199), determinando hasta qué punto está justificada en relación con factores como el lector, la intención del traductor y el momento histórico en que se publica el texto (Hatim y Mason 1998; Brunette 2000).

Teniendo en cuenta estos aspectos se ha analizado el papel del narrador en diferentes adaptaciones literarias infanto-juveniles de la obra de Miguel de Cervantes El ingenioso hidalgo don Quijote de la Mancha (1605) a la lengua inglesa ${ }^{1}$, lo que

1. Se han analizado las adaptaciones literarias para niños y jóvenes publicadas en lengua inglesa identificadas durante la investigación relativa al proyecto de investigación: "Traducciones/adaptaciones 
lleva a un estudio más pormenorizado de aquellas obras en las que el narrador del texto meta difiere en gran manera del narrador de la obra de Cervantes. Por ello este estudio se centrará en la adaptación de Eisner The Last Knight. An Introduction to Don Quixote (2000), la adaptación literaria para primeros lectores Wishbone Classics. Don Quixote (1996) de Burgan y la novela gráfica de Davis Don Quixote (2011). Además se ha considerado el papel de las interpelaciones al lector en la adaptación de Kimmel (2004) Don Quixote and the Windmills y en la de Reit (2007) Great Heroes. Don Quixote.

\section{Adaptaciones literarias analizadas}

La adaptación de obras literarias para adultos en obras de literatura infantil y juvenil ha sido siempre parte esencial del canon literario. El Quijote de la Mancha es uno de los clásicos que se ha traducido a más lenguas y que se ha adaptado en diferentes formatos y para diferentes receptores. A pesar de que el número de obras infantiles traducidas al inglés ha sido siempre reducido debido a la relevancia de esta lengua, la influencia de algunas de las primeras traducciones y adaptaciones de El Quijote en la literatura inglesa es incuestionable (Lathey 2010: 10) y el número de adaptaciones infantiles y juveniles que se publica en la actualidad sigue siendo considerable.

Al tratase de adaptaciones literarias de una de las mejores obras de la literatura universal, cabe esperar que el texto meta se haya abreviado y simplificado para adaptarse a las destrezas del receptor (Pascua 1998; Sotomayor 2005). La norma de la integridad del texto se acepta en traducciones y adaptaciones del sistema canónico adulto frente a la norma de modelos simplificados prominente en la literatura infantil y juvenil (Lefebvre 2012), a pesar de lo cual se puede observar que, en general, las adaptaciones de El Quijote a la lengua inglesa recogen los episodios más conocidos del texto fuente, en muchos casos de las dos partes de la obra. Se reducen tramas secundarias, monólogos y diálogos largos y complejos sin modificar el argumento principal ni los personajes, siguiendo la tendencia de evitar una compleja caracterización (Shavit 2006: 36), en aras de lograr que el niño se acerque por primera vez a un texto clásico (Ghesquiere 2006: 19) que se ajuste a sus posi-

literarias y audiovisuales de El Quijote para niños y jóvenes en los sistemas lingüístico-culturales de Europa (I)" financiado por el Ministerio de Ciencia e Innovación, Subdirección General de Proyectos de Investigación con referencia FFI2008-05298/FILO. 
bilidades cognitivas, lingüísticas y de atención y que le permita mantener el interés por la obra de Cervantes en años posteriores desde una nueva perspectiva:

\begin{abstract}
A pesar de los elementos simplificados, distorsionados o edulcorados que puedan contener, lo cierto es que las adaptaciones van abriendo las puertas al conocimiento. Luego, ya de adultos en manos de cada uno está el traspasarlas para incluir nuevos puntos de vista sobre la historia o cerrarlas para siempre (Lorenzo 2008: 103).
\end{abstract}

En conclusión, las adaptaciones literarias dirigidas a niños y jóvenes introducen al receptor meta en una obra clásica, por lo que su formato y características tienen que ser atractivas para el lector, lo que a su vez puede justificar modificaciones importantes del texto fuente como por ejemplo omisiones y expansiones, introducción de elementos no verbales, simplificaciones, cambios en los personajes y cuestiones de registro. Entre las modificaciones más significativas encontradas al analizar las adaptaciones literarias infantiles y juveniles de El Quijote a la lengua inglesa destacan las relativas a la estrategia narrativa, que son la base de este estudio y que se estudiarán en las obras analizadas teniendo en cuenta su contexto.

\title{
2.1. La adaptación de Burgan (1996)
}

La adaptación de Burgan (1996) Wishbone Classics. Don Quixote constituye el primer volumen de una colección de libros que adapta clásicos de la literatura universal para un receptor infantil mayor de 8 años. Entre las obras clásicas que se adaptan en esta colección se incluyen obras tan conocidas en la cultura meta como Romeo and Juliet, Oliver Twist, Robin Hood, Tom Saywer, Ivanhoe y Joan of Arch. En 127 páginas, 19 capítulos y un epílogo la adaptación recoge la esencia de la obra de Cervantes, incluyendo los episodios más conocidos y gran parte de los rasgos centrales del texto fuente. El texto meta es una recreación muy sencilla y simplificada de los aspectos del texto fuente que más pueden atraer e interesar al lector. Los ilustradores del relato son Hokanson y Cichetti, mientras que Kathryn Yingling se encarga de las imágenes de Wishbone, el perro protagonista y el narrador de la obra, un narrador en primera persona que introduce la figura de don Quijote a los niños. Wishbone es el protagonista de una serie de TV, por lo que, al tratarse de un personaje conocido y atractivo para los niños, se crea un ambiente familiar en el que el niño se puede sentir más cómodo para disfrutar de la lectura y acercarse por primera vez a esta obra clásica, lo que facilita la consecución de objetivos didácticos y lúdicos. El propio Wishbone introduce la novela de Cervantes de esta forma: 
Often I am the main character and sometimes I'm the sidekick, but I'm always right in the middle of a thrilling story. Now, I'm going to be your guide as we explore one of the world's greatest books - DON QUIXOTE. Together we'll meet a lot of interesting characters and discover places that we've never been! (Burgan 1996: 5).

Los comentarios del perro Wishbone se suceden a lo largo del texto. Están marcados en negrilla y pretenden hacer partícipe al lector de la historia y explicar todo lo que sucede desde su peculiar punto de vista, creando situaciones muy divertidas o también clarificando aspectos que pueden resultar difíciles para el lector (Cadden 2010: xi), a la vez que se destacan continuamente los valores positivos que encarna el caballero protagonista, don Quijote, como por ejemplo la amistad, la verdad, la valentía y la lealtad (Salmerón 2004: 122, 322). Después de la aventura con los monjes, por ejemplo, Wishbone compara con humor la situación por la que atraviesa el protagonista con su propia vida, a la vez que le pregunta al lector sobre cómo cree que se desarrollará la obra:

Don Quixote isn't the only one who confronts the forces of evil. I have to deal with cats and dogs catchers almost every day. Now, what new adventure is in store for our brave knight? Will it be something wonderful —or something terrible? (Burgan 1996: 35).

Esa comparación entre los peligros y las fuerzas del mal a las que tanto Wishbone como don Quijote se tienen que enfrentar pretende transmitirle al lector confianza y cercanía, algo a lo que también contribuyen las preguntas del narrador al lector. De esta forma se crea en el texto una figura que Schwenke (2003: 186) denomina engaging narrator porque el narrador busca atraer al lector, invitarlo a participar en la acción, a que se acerque a la figura del protagonista: "Immediateengaging-first-person narration [...] precludes both an adult narrator and the use of dramatic, romantic, and structural irony in the representation of the narrator-protagonist". De hecho, Wishbone busca continuamente la complicidad del lector, quiere que participe, que piense en lo que está sucediendo y lo que va a suceder, estimulando de esta forma sus capacidades. En el capítulo 10 titulado "Sancho plays a Trick", por ejemplo, Wishbone comienza el relato comentando: "Sancho Panza heads back up the mountain with a note from Dulcinea. Will Don Quixote believe Sancho has been to El Toboso and met the fair lady of his dreams?" (Burgan 1996: 69). Estas preguntas al lector hacen que éste se involucre más en el relato y pretenden convertirlo en protagonista de la obra (Wall 1991: 35; Hunt 2001: 461). No cabe duda de que estas frases también encierran un mayor o menor interés didáctico, ya que contribuyen a formar al lector (Ezpeleta 2011: 106) y no se puede olvidar que la obra está dirigida a mayores de 8 años. 
Las imágenes del texto subrayan también el importante papel del perro narrador porque el mayor número de imágenes corresponde a Wishbone y no a don Quijote. Las imágenes, por tanto, consolidan el papel del narrador y permiten al lector aprender y disfrutar de la lectura (Tabernero 2005: 90). A lo largo de todo el texto, en prácticamente todas las páginas, se incluyen divertidos bocetos de Wishbone en blanco y negro en los que siempre se ve al perro en movimiento e incluso parece que sonríe o habla, mostrando una cierta complicidad con el lector, como si éste fuese un personaje más de la obra. Estas imágenes se intercalan con nueve imágenes de don Quijote, también en blanco y negro, que reflejan diferentes aspectos de la narración. La imagen de la portada interior recoge uno de los momentos más emblemáticos del texto: don Quijote a punto de luchar contra un molino de viento. La única imagen en color del texto es la de la portada de la obra. En ella se puede ver a Wishbone vestido con el atuendo típico de la época en que se sitúa la novela de Cervantes.

Se puede concluir por tanto que, a pesar de las modificaciones que implica, la inclusión de un personaje nuevo en la obra, de Wishbone, presenta aspectos muy positivos puesto que, mediante esta estrategia narrativa, el lector meta conoce al personaje que le está contando la historia, disfruta de sus comentarios y del humor que crea mientras se sumerge por primera vez en una de las mejores, y a su vez más complejas, obras de la literatura universal. Las decisiones del adaptador giran en torno a la edad, el nivel intelectual y cultural del receptor y los valores didácticos que pretende transmitir, factores que justifican las modificaciones, ya que su intención es una primera aproximación a una obra realmente compleja publicada en una lengua diferente.

\subsection{La adaptación de Eisner (2000)}

La segunda obra analizada en este trabajo, la adaptación de Eisner The Last Knight. An Introduction to Don Quixote (2000), es una breve adaptación de 32 páginas en formato cómic que solo incluye el conocido episodio de los molinos, después de haber explicado cómo el personaje principal decide convertirse en caballero andante tras la continua y obsesiva lectura de libros de caballerías. La obra está dirigida a niños mayores de 9 años. Su autor, el estadounidense Will Eisner, es uno de los autores pioneros en el género de la novela gráfica y uno de los mejores autores de este género ${ }^{2}$.

2. Eisner creó el personaje The Spirit en 1941. Su obra A Contract with God (1978) supone el inicio de la novela gráfica y la renovación integral del cómic. 


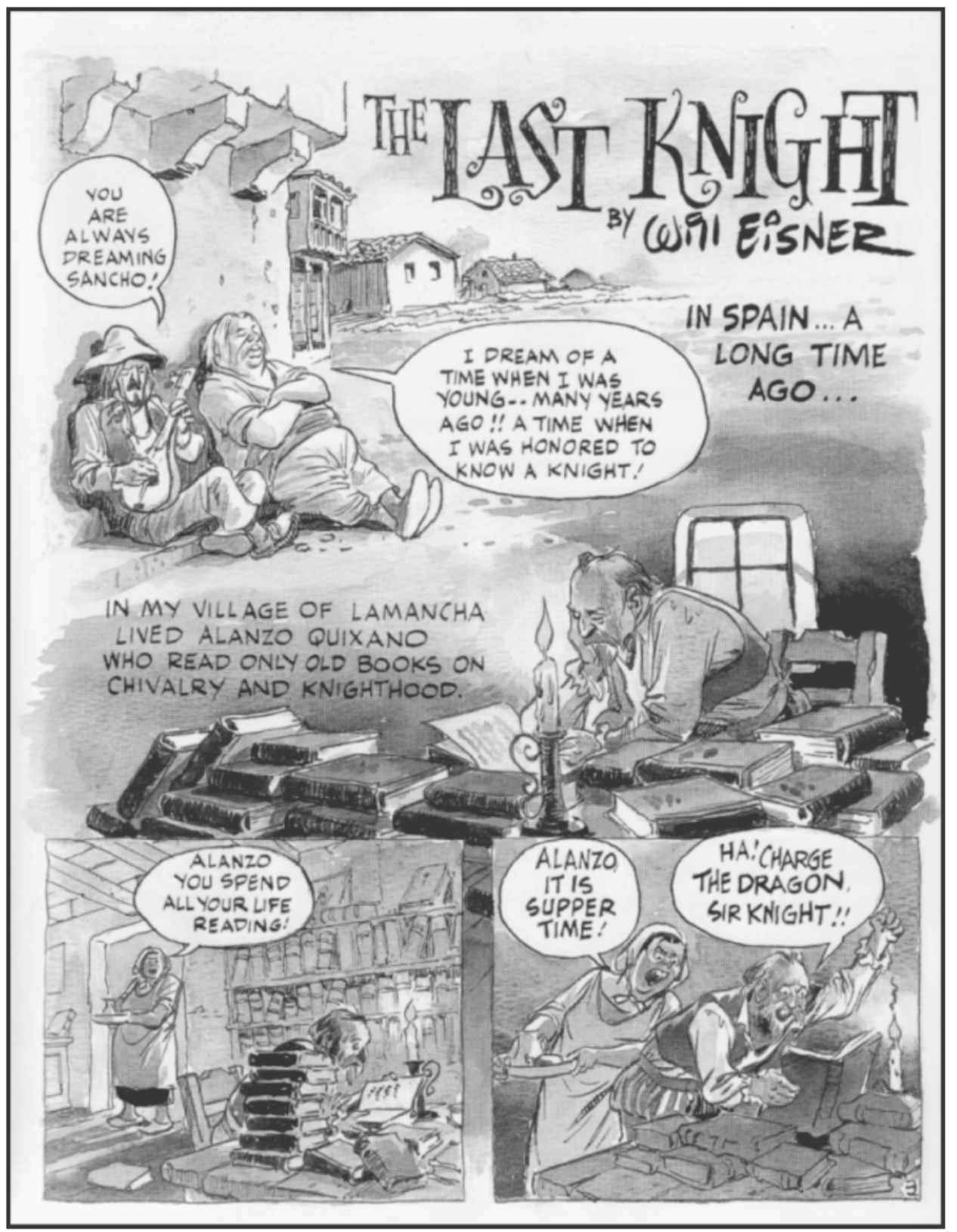

Figura 1. El narrador en la adaptación de Eisner (2000). 
Una de las características centrales de esta adaptación reside en el hecho de que el narrador de la misma es Sancho Panza. Él es el que relata la historia e incluso el propio escritor del texto fuente, Miguel de Cervantes, será uno de los personajes que aparezcan en las viñetas finales (Eisner 2000: 31). El escudero aparece al comienzo de la obra sentado al lado de otro campesino que toca una bandurria, lo que parece evocar la figura de un trovador, quizás para intentar situar al lector en un contexto arcaico y evocar la raíz popular del personaje de la novela de Cervantes (Flores 1982). Esta disposición parece enfatizar también el carácter sencillo del escudero, incluso su simpleza. Las apariciones de Sancho como narrador se centran al principio y al final de la obra mientras que en las viñetas las frases del narrador se reducen a la mínima expresión. Los tonos de las imágenes en que aparece directamente Sancho como narrador son diferentes. Se trata de imágenes en tonos grises, en claro contraste con el color de las demás viñetas que cuentan el desarrollo de la acción, subrayando de esta forma el papel del personaje-narrador. Los tonos grises parecen evocar lo negativo de la realidad frente al esplendor del recuerdo y la juventud que se refleja en las ilustraciones en color de la historia. Este juego de colores es muy importante porque el papel de las ilustraciones es esencial para que el niño se interese por la obra. El impacto de los elementos visuales en el lector es especialmente significativo, ya que facilita en gran manera la comprensión del texto y enfatiza los aspectos lúdicos (Oittinen 2006: 94). Las imágenes presentan a personajes que ofrecen confianza y los tonos son claros y con colores pastel, logrando crear un contexto agradable para el receptor.

Sancho narra la historia como testigo directo de la misma, como un testigo que está cuerdo ${ }^{3}$ y que se presenta como un personaje cercano, lo que puede facilitar sin duda la credibilidad del niño. Al comienzo del relato Sancho afirma: "I dream of a time when I was young... Many years ago!! A time when I was honoured to know a knight" (Eisner 2000: 3). Sancho cuenta la historia desde la madurez de una persona adulta, quizás para justificar su insensatez cuando siendo joven acompañó a un caballero a pesar de que todos creían que estaba loco. De esta forma los niños a los que va dirigida la obra pueden aprender que no deben imitar este comportamiento, que deben evitar caer en obsesiones y locuras de cualquier tipo.

En la frase siguiente que pronuncia Sancho el uso del adjetivo posesivo "my" enlazará ese narrador en primera persona con el narrador en tercera persona que

3. Sancho se presenta como un personaje cuerdo frente a su loco amo, aunque en algunas ocasiones no se sabe quién está más loco, el amo o el criado. De hecho, Sancho es el arquetipo del tonto-listo o del necio-astuto (Montero 1997: 53-54). 
predomina en la obra: "In my village of La Mancha lived Alanzo Quixano who read only old books on chivalry and knighthood" (Eisner 2000: 3). Las intervenciones del narrador serán muy breves y predominarán los diálogos. Las imágenes grises de Sancho narrador vuelven a aparecer después del episodio del león al final del libro, cuando se recupera su presencia en la obra: "Well, that did begin the legend. The stories of Don Quixote's adventures were written into books" (Eisner 2000: 29). Este interés por el carácter y difusión universal de la obra vuelve a quedar patente al final del libro. Después de la enfermedad de don Quijote y de su muerte Sancho concluye, evocando el tono de leyenda al comienzo de la obra "de cuyo nombre no quiero acordarme":

Honored by the great author Miguel Cervantes... read by millions over many generations...' When questioned about if he really lived Sancho answered: 'it doesn't matter... maybe he did and maybe he didn't... but what is most important is that his dream surely did' (Eisner 2000: 32).

A modo de conclusión del relato, y recurriendo otra vez a la figura de Sancho narrador, se subraya la importancia de la figura legendaria del protagonista, de su valor en la literatura universal, lo que vuelve a poner de relieve la posible intención del adaptador: acercar al niño a una obra imprescindible en el canon literario y ensalzar los valores humanos que transmite. Esta es la razón que puede justificar la estrategia narrativa, la visibilidad del traductor. La variación del papel de Sancho Panza contribuye a que el receptor implícito infantil se enfrente a una obra interesante, con la que disfrute leyendo y, al mismo tiempo, pueda mejorar su vocabulario y otros aspectos lingüísticos, a la vez que consolida sus valores morales de referencia.

\subsection{La adaptación de Davis (2011)}

La novela gráfica de Davis Don Quixote (2011) presenta también importantes diferencias con respecto al narrador del texto fuente. En este caso el narrador es el propio escritor, Cervantes. En la portada interior se afirma que Cervantes escribió la obra mientras estaba encarcelado en Sevilla: "Cervantes conceived of Don Quixote whilst he was imprisoned in Seville" (Davis 2011: 3). A continuación aparece una imagen que se va a repetir con cierta frecuencia a lo largo del texto meta. Se trata de una voz que, entre rejas como refleja la figura 2, comenta diferentes aspectos siempre dirigidos directamente al receptor buscando su participación como si se tratase de un diálogo directo entre lector y narrador. 


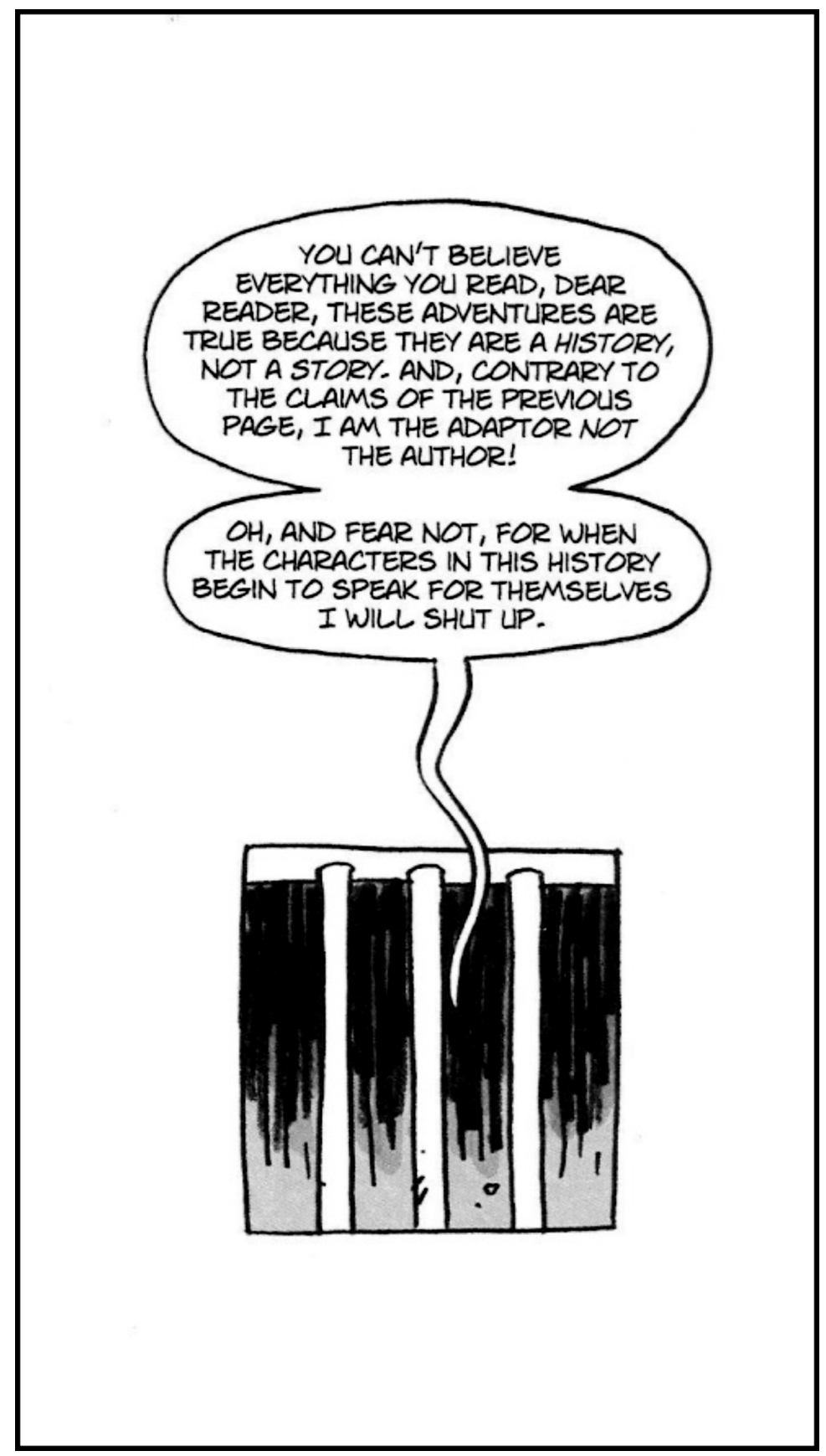

Figura 2. Segunda intervención del narrador en la adaptación de Davis (2011). 
Como se ve en la figura 2 la voz niega ser el autor de la obra pero admite ser el adaptador. Es relevante también la diferencia entre los términos "history" y "story", ya que de esta forma se insiste en la veracidad del relato al ponerlo al nivel de un hecho histórico, destacando así su relevancia.

Estas inclusiones directas del narrador se intercalan en la obra en momentos concretos, como luego veremos, mientras que en los demás casos las intervenciones del narrador siguen la línea convencional de este tipo de relatos: frases breves de un narrador en tercera persona en cajas cuadradas que no recogen ningún tipo de comentario sobre lo que acontece. El propio narrador lo anticipa, después de la imagen anteriormente comentada, recordándole al lector que él es el que siempre cuenta la historia: "My voice now appears in these boxes, so if you see one of these boxes you'll know it's me speaking" (Davis 2011: 6).

El narrador aparece de forma visible y explícita en varias ocasiones más a lo largo de la obra, prácticamente siempre representado como una voz entre rejas (Davis 2011: 26, 40, 55, 69, 117, 133, 138, 148), comentando brevemente los hechos e insistiendo en la veracidad de todo lo que está contando, porque así consta en el manuscrito que maneja para relatar la historia y que él solo adapta y pone en conocimiento del lector. El narrador siempre deja claro que él no es el autor, que es el "second undertaker of this history" (Davis 2011: 39).

Esta novela gráfica destaca también por la inclusión de algunas de las historias interpoladas de la obra de Cervantes. El hecho de que la novela gráfica está dirigida a un público juvenil, o incluso adulto ${ }^{4}$, puede justificar en cierta manera esta inclusión puesto que estas adaptaciones suelen ser más completas y cercanas a las traducciones para adultos. En este caso los relatos del texto fuente aparecen como atractivas historias ${ }^{5}$ separadas del resto del texto en las que se juega con el color de las viñetas para marcar sus diferencias y particularidades. Este juego de colores se repite a lo largo de toda la obra.

La complejidad del papel del narrador en esta obra es importante, si bien es verdad que la edad del receptor lo permite. Tampoco se puede olvidar que una de las características de la novela gráfica reside en la interpretación del texto por parte

4. Se podría aplicar el concepto de doble receptor ya que la obra está dirigida al lector juvenil y al público adulto (Oittinen 2006: 41).

5. Se incluyen las historias de Grisóstomo y Marcela ("The Goat Herder's Tale", 2011: 47), Cardenio y Luscinda ("Cardenio's Tale", 2011: 98, 108) ("Dorotea's Tale", 2011: 112) y la novela del curioso impertinente ("The Novel of the Curious Impertinent", 2011: 122-123, 126). 
del lector (Russ 2012). En todo momento el adaptador busca la complicidad y el interés del lector, siguiendo la estrategia narrativa comentada con anterioridad en el caso de la adaptación de Eisner. Por ello en la mitad de la aventura del Vizcaíno interrumpe la acción y el narrador Cervantes desde la cárcel explica cómo compró la historia de don Quijote que le vendió Cide Hamete Benengeli. Esta historia ocupa dos páginas (Davis 2011: 40-41). La inclusión de la figura de Cide Hamete Benengeli es un hecho especialmente relevante porque se trata de una figura ignorada en la mayoría de las adaptaciones infantiles y juveniles de la obra a la lengua inglesa. Cide Hamete es un personaje creado por Cervantes, un historiador musulmán que, según el propio Cervantes, fue el que realmente escribió parte de la historia a partir del capítulo IX. La presencia de este elemento metaficcional parece quererle dar más credibilidad a la obra. Este puede ser también el objetivo del adaptador a la lengua inglesa al incluir este elemento. El narrador insiste en que él compró la historia y en varios momentos le recuerda al lector este hecho para conseguir su credibilidad repitiendo que él se limita a adaptar la historia (Davis 2011: 55, 69).

Por ello esta necesidad de credibilidad puede justificar las intervenciones del narrador Cervantes al final de la obra. Desde la cárcel consigue hablar con Sancho Panza, al que le da el final de la historia que había comprado (Davis 2011: 143-144). Don Quijote está enjaulado y en el momento en el que Sancho planea cómo el caballero puede huir el propio Sancho Panza aparece al lado de la imagen de la voz entre rejas. Durante la conversación, en la que Sancho no entiende nada, la voz le da a Sancho el final de la historia. Al regresar a casa, después de que don Quijote se lastimase al confundir a unos penitentes que llevaban a una imagen de la Virgen María en procesión con una princesa secuestrada, Sancho intenta darle la obra a don Quijote pero el bachiller y el sacerdote se quedan con ella y ven que es el epitafio de don Quijote, Sancho y Dulcinea. El narrador afirma: "Sadly, I have been unable to discover whether a third sally of Don Quixote ever took place. The last of the pages I bought from the boy in the market is the page I gave to Sancho..." (Davis 2011: 148). Insiste nuevamente en que ha comprado la historia y se limita a contar lo que está escrito.

Después de todas estas intervenciones del narrador destaca el final de la obra, ya que el relato termina con los epitafios de don Quijote, Sancho y Dulcinea (teniendo en cuenta que en el texto fuente el único personaje que fallece es don Quijote) y a continuación el narrador, nuevamente entre rejas, concluye: "Thank you for joining me in here for this history. I hope to escape will be easier for you than it is for me. Then again, is it possible to escape a book like Don Quixote?" (Davis 2011: 151). El narrador subraya de esta forma la aceptación positiva que espera el autor de la adaptación por parte del receptor. 

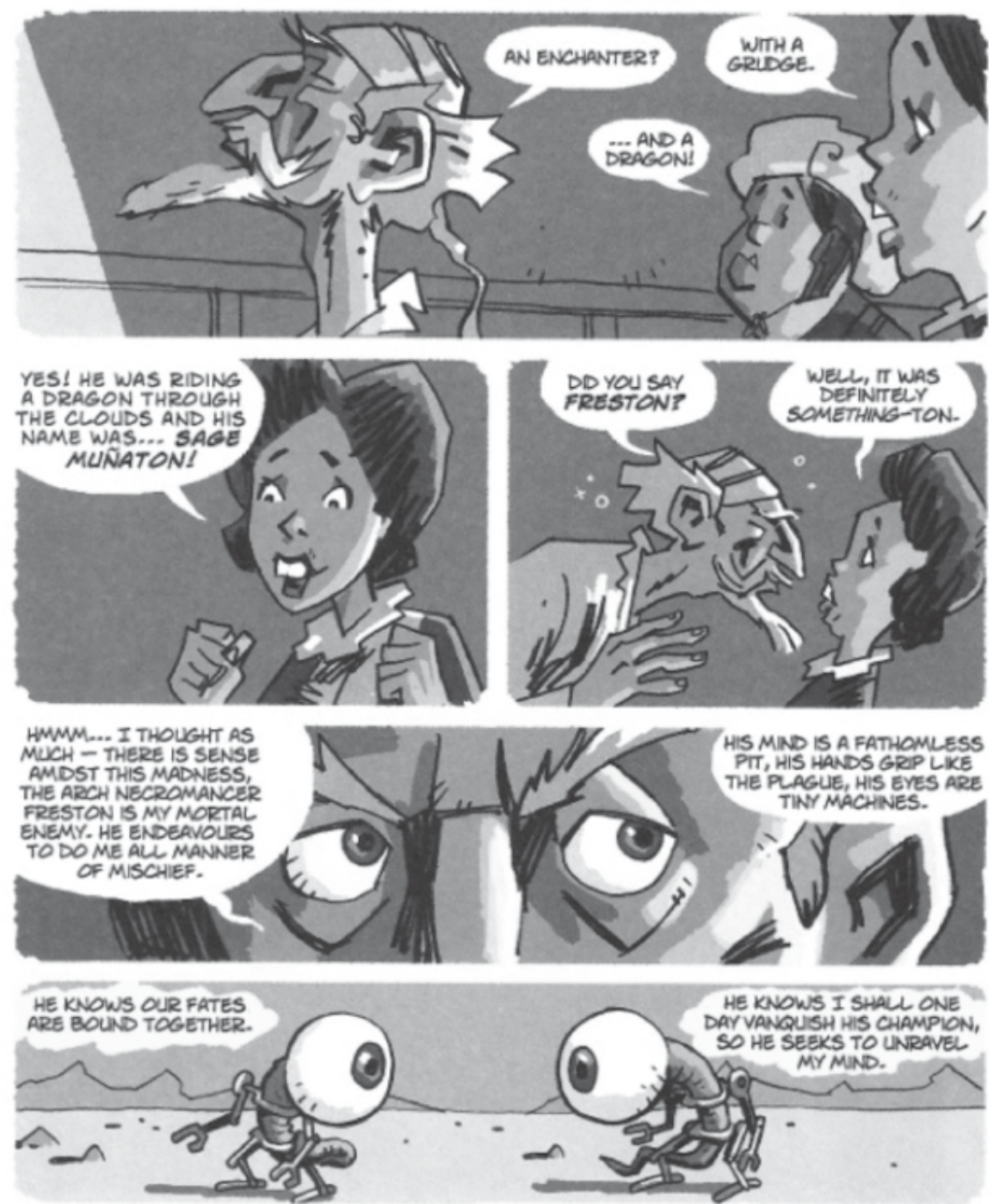

THOU CANST NOT MAGINE WHAT IT IS, SWEET NIECE, TO HAVE
ANOTHER CONSPIRING AGAINST ONE'S WITS.

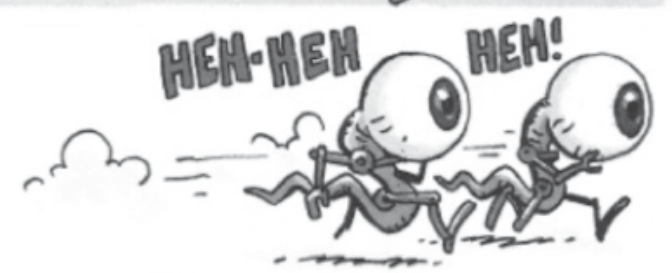

Figura 3. Los ojos de don Quijote narran la historia. 
Además de la complejidad del papel del narrador hay que tener en cuenta casos especiales, más complejos si cabe, que vuelven a incidir en la participación del lector y en la necesidad de que interprete el texto. Los ojos de don Quijote también actúan como narradores hablando entre ellos y con su sobrina después de la quema de sus libros de caballería en la biblioteca, como refleja la figura 3. El narrador los introduce como pequeñas máquinas, "tiny machines" (Davis 2011: 26).

Los ojos del personaje principal aparecen humanizados con pies y brazos mientras comentan en referencia a la figura de Freston que acaba de mencionar el protagonista: "He knows our fates are bound together", "He knows I shall one day vanquish his champion, so he seeks to unravel my mind" (Davis 2011: 28). El sabio Frestón es, según don Quijote, el responsable del encantamiento de su biblioteca, aunque en realidad su sobrina y su ama fueron las responsables de la quema de los libros de caballería para intentar evitar la locura del hidalgo. La presencia de los ojos constituye todo un desafío interpretativo por parte del lector y se repite al terminar la famosa aventura de los molinos de viento, momento en el que los ojos aparecen corriendo después de que don Quijote afirmase que el sabio Frestón es también el responsable de la transformación de los molinos en enormes gigantes pero que no será capaz de derrotarlo: "Worry not though, my squire, this means we have him on the run. His evil arts will never defeat my trusty word..." (Davis 2011: 35).

\subsection{Otras adaptaciones}

Además de estas adaptaciones en las que se crea un narrador, un personaje nuevo, que trasmite cercanía y complicidad al lector, se pueden destacar dos adaptaciones que presentan un narrador que también interpela al lector pero este hecho solo sucede una vez en cada una de las obras.

La adaptación de Kimmel (2004), Don Quixote and the Windmills, solo consta de 34 páginas y recoge, como su nombre indica, el conocido episodio de los molinos en el que se relata como don Quijote confunde a dichos molinos con enormes gigantes que lo quieren atacar después de haber explicado que la lectura de libros de caballería ha llevado al hidalgo a convertirse en el caballero don Quijote de la Mancha.

La adaptación está claramente dirigida al público infantil a partir de 5 años, ya que el texto es breve (solo ocupa la mitad de las páginas situadas a la derecha, las frases son muy cortas y predomina el diálogo entre don Quijote y Sancho) y las ilustraciones cubren las dos páginas. Los colores de las imágenes son vivos, prin- 
cipalmente en tonos pardos, verde y azul, y las imágenes de cuerpo a completo recogen rostros muy expresivos de los personajes.

Al comienzo del relato el narrador se dirige directamente al lector haciéndolo partícipe de la obra y advirtiéndole de los peligros de leer libros de caballería, una afirmación que parece algo exagerada:

Are you one who loves old stories? Does your heart beat faster when you hear tales of knights in armor? Of castles and dragons? Of ogres, sorcerers, and damsels in distress? Beware! Those tales can drive you mad. It happened to a certain Spanish gentleman who lived four centuries ago in the province of La Mancha (Kimmel 2004: 4).

El narrador incide en las imágenes de aventuras que se ofrecen en la mayoría de las adaptaciones infantiles a la lengua inglesa mencionando aquellos elementos que más pueden atraer al niño como por ejemplo los caballeros, los dragones, los castillos y las damiselas en peligro. Sin embargo, parece algo excesiva la afirmación de que la lectura de los libros de caballería lleva inexorablemente a la locura. El narrador parece querer prevenir al receptor, que en este caso es un lector de corta edad, de los peligros a los que está expuesto. Además, como el ejemplo que se introduce hace referencia a un caballero español el receptor meta puede hacerse una idea equivocada de las diferencias culturales entre los dos países.

El narrador de la adaptación de Reit Great Heroes. The Legends of King Arthur. Don Quixote. The Adventures of Sherlock Holmes (2007) también es un narrador en tercera persona que parece distante en todo el relato. La obra está dirigida a un público juvenil. Se incluye dentro de la colección "Bank Street. Graphic Novel" y consta solo de 17 páginas. Como el título indica, el volumen recoge otras dos adaptaciones de obras canónicas en la cultura meta. Las palabras del narrador aparecen en un bocadillo con forma arcaica, algo que solo sucede en esta adaptación y en la de The Legends of King Arthur. Solo al final del libro el narrador se dirige al lector haciéndolo reflexionar: "Was Don Quixote right? What do you think?" (Reit 2007: 37). Esta pregunta hace referencia a las palabras de don Quijote en su lecho de muerte en las que ensalza los valores de un héroe, de un caballero: "I have pursued my dreams... and now it is time... for me to die. My body ends... but the things that I loved... courage... honor... beauty... the triumph of good over evil... these will not die... they will live on... for ever..." (Reit 2007: 37). El objetivo didáctico de estas frases está claro y coincide con la intención de la colección a la que pertenece el volumen, intención que aparece claramente definida en la contraportada de la obra: "Developed by Bank Street College of Education, long 
a trusted and respected named among educators, these novels are sure to encourage readers to read the originals" 6 . Por tanto, en este caso y en el caso anterior la intervención del narrador, a pesar de su brevedad, incide en los aspectos pedagógicos y la edad del lector implícito.

\section{Conclusiones}

La creación de un personaje que actúa como narrador resulta especialmente atractiva para el receptor, para el lector implícito del texto meta. Wishbone introduce al niño en la historia y lo sitúa en un contexto agradable, casi familiar, que le permite disfrutar de la lectura y asimilar mejor los nuevos conceptos que quiere transmitir el texto. Lo mismo se puede afirmar en relación con la estrategia narrativa utilizada por Eisner, aunque sí es verdad que a primera vista puede sorprender el papel de Sancho Panza como narrador. Sin embargo, de la pareja de protagonistas Sancho es el más cuerdo, el más sencillo, el más tierno y agradable. En los dos casos el adaptador consigue darle más credibilidad al relato y las características de las imágenes que acompañan al texto inciden en el objetivo de lograr acercar una obra del canon literario al receptor infantil y/o juvenil que pertenece a un sistema lingüístico y cultural diferente. El narrador comenta la historia y se dirige al lector consolidando también los objetivos didácticos de la adaptación, si bien es verdad que a veces estas intervenciones podrían dejar poco margen de maniobra a las reflexiones del propio lector (Nikolajeva 2005: 25).

La edad del receptor ha sido un factor clave a la hora de analizar la estrategia narrativa de cada adaptación. La adaptación de Davis dirigida a un público juvenil o incluso adulto presenta un punto de vista muy innovador y una estrategia narrativa muy compleja que desafía el nivel intelectual del receptor y su agudeza lectora, algo a lo que también contribuye la inclusión de la figura de Cide Hamete y el planteamiento tan atractivo con el que se presentan las historias interpoladas en el texto fuente.

Es interesante tener en cuenta que los textos, excepto la adaptación de Burgan (1996), pertenecen al género del cómic o a la novela gráfica, un arte que ha conseguido tener un papel esencial en el mercado editorial de estos últimos años (García 2010). La importancia de esta industria, sobre todo en Estados Unidos que es

6. Esta adaptación se había publicado en 1990 por primera vez en Boy's Life, la revista de los Boy Scouts de Estados Unidos. 
el lugar en el que se han publicado las adaptaciones analizadas, está fuera de toda dudas, ya que su auge ha sido considerable en estos últimos años (Russ 2012). De hecho las adaptaciones con este formato que se han analizado se han publicado en el siglo XXI. Es un formato de libro muy atractivo que engancha al lector y que puede ser una buena introducción a las obras clásicas de la literatura universal para un lector infantil o juvenil.

Como ha demostrado el análisis, la estrategia narrativa se adapta al lector, a sus capacidades cognitivas, reforzando su papel con el juego de las imágenes y el tipo de texto, contribuyendo de esta forma a lograr los objetivos lúdicos y pedagógicos planteados, logrando que la adaptación acerque el receptor a una obra tan compleja que presenta un importante grado de dificultad y está situada en un sistema cultural diferente, pero al fin y al cabo una obra imprescindible.

\section{Bibliografía}

BRUNETTE, L. (2000). “A Comparison of TQA Practices”. The Translator 6 (2): 169-182.

BURGAN, M. (1996). Wishbone Classics. Don Quixote. New York: Harper Papers.

CADDEN. M. (Ed.) (2010). “Introduction" en Telling Children's Stories: Narrative Theory and Children's Literature. Lincoln \& London: University of Nebraska Press, pp. vii-Xxv.

CHATMAN, S. (1978). Story and Discourse. Narrative Structure in Fiction and Film. London: Ithaca.

DAVIS, R. (2011). Don Quixote. New York: Self-made Hero.

EISNER, W. (2000). The Last Knight. An Introduction to Don Quixote. New York: NBM.

EZPELETA AGUILAR, F. (2011). "La formación del lector como tema en la última narrativa infantil y juvenil". Ocnos 7: 101-110.

FLORES, R. M. (1982). Sancho Panza through Three Hundred Seventy-five Years of Continuations, Imitations and Criticism 1605-1980. Newark, Delaware: Juan de la Cuesta.

GARCÍA, S. (2010). La novela gráfica. Bilbao: Astiberri.

GHESQUIERE, R. (2006). "Why does Children's Literature Need Translations?" en Children's Literature in Translation. (Eds. J. Coillie, y W. P. Verschueren). Manchester: St. Jerome Publishing, pp. 19- 33.

HATIM, B. y MASON, I. (1997). The Translator as Communicator . London: Routledge. 
HUNT, P. (2001). Children's Literature. Oxford: Wiley-Blackwell.

KIMMEL, E. (2004). Don Quixote and the Windmills. New York: Farrar, Straus and Giroux.

LATHEY, G. (2010). The Role of Translators in Children's Literature: Invisible Storyteller. London: Routledge.

LEFEBVRE, B. (2012). Textual Transformations in Children's Literature. Adaptations, Transformations, Reconsiderations. London: Routledge.

LORENZO GARCÍA, L. (2008). "Estudio del doblaje al español peninsular de Pocahontas (Disney)" en Diálogos intertextuales 1: Pocahontas. (Ed. V. Ruzicka). Frankfurt and Main: Peter Lang, pp. 89-106.

MONTERO REGUERA, J. (1997). El Quijote y la crítica contemporánea. Madrid: Centro de Estudios Cervantinos.

NIKOLAJEVA, M. (2005). Aesthetic Approaches to Children's Literature: An Introduction. New York: Scarecrow Press.

OITTINEN, R. (2006). "No innocent Act: On the Ethics of Translating for Children" en Children's Literature in Translation. (Eds. J. Coillie, y W. P. Verschueren). Manchester: St. Jerome Publishing, pp. 35-46.

O'SULLIVAN, E. (2003). "Narratology meets Translation Studies, or, the voice of the Translator in Children's Literature". Meta 48 (1-2): 197-207.

PASCUA FEBLES, I. (1998). La adaptación en la traducción de la literatura infantil. Las Palmas de Gran Canaria: Universidad de las Palmas de Gran Canaria.

REIT, S. (2007). Great Heroes. The Legends of King Arthur. Don Quixote. The Adventures of Sherlock Holmes. (Il. Ernie Colón). New York: Gareth Stevens.

RUSS, K. (Ed.) (2012). The Graphic Canon. The World's Greatest Literature as Comic and Visuals. V. 1. New York: Seven Stories Press.

SALMERÓN VÍLCHEZ, P. (2004). Transmisión de valores a través de los cuentos infantiles clásicos. Granada: Editorial de la Universidad de Granada. Tesis doctoral.

SCHWENKE, W. A. (2003). "The Value of Singularity in First- and Restricted Third-Person Engaging Narration”. Children's Literature 31: 116-141.

SHAVIT, Z. (2006). “Translation of Children's Literature” en The Translation of Children's Literature: A Reader. (Ed. G. Lathey). Clevedon: Multilingual Matters, pp. 25-40.

SOTOMAYOR SÁEZ, V. (2005). "Literatura, sociedad, educación: las adaptaciones literarias". Revista de educación, número extraordinario: 217-238.

TABERNERO SALA, R. (2005). Nuevas y viejas formas de contar. El discurso narrativo infantil en los umbrales del siglo XXI. Zaragoza: Prensas Universitarias de Zaragoza. 
TOLEDANO BUENDÍA, C. (2001-2002). "Traducción y adecuación de la literatura para adultos a un público infantil y juvenil". Cuadernos de investigación filológica 27-28: 103-120.

VENUTI, L. (1995). The Translator's Invisibility. A History of Translation. London, New York: Routledge.

WALL, B. (1991). The Narrator's Voice: The Dilemma of Children's Fiction. London: McMillan. 